Ciencia y tecnología Science and Technology 



\title{
Validación del efecto de remediación y refinación catalítica de los catalizadores EcoEvol y su efecto en la mejora en la performance de motores a combustión interna
}

\author{
Darío Eder Lazo Hoyos* \\ Rodrigo Coquis Sánchez-Concha* \\ Greentech Innovations SAC
}

Recibido: 08 de mayo del 2016 / Aprobado: 21 de setiembre del 2016

RESUMEN: Los motores a combustión interna son usados para distintas actividades económicas como el transporte, la generación de electricidad, minería, entre otras aplicaciones. Un insumo clave para su funcionamiento son los combustibles fósiles, principalmente el diésel y la gasolina. Un factor poco difundido y que afecta directamente la performance de los combustibles es la contaminación microbiológica. En tal sentido, el catalizador EcoEvol C fue diseñado para eliminar esta contaminación, propiciar mejores condiciones de funcionamiento en los motores, generar la reducción de emisiones, ahorrar combustible y aumentar de potencia.

Palabras clave: motores a combustión interna / contaminación microbiana / combustible

\section{Validation of the EcoEvol fuel catalyst remediation and refining efect and its effect on improving performance in internal combustion engines}

ABSTRACT: Internal combustion engines are widely use in several economical activities such as transport, power generation, mining, etc. Fossil fuels, especially gasoline and diesel, are a crucial input for their operation. A little known factor that affects its performance is their microbiological contamination. In this regard, the EcoEvol C fuel catalyst was engineered to solve this problem, promoting better operating conditions for internal combustion engines, generating reductions in polluting exhaust emissions, fuel savings and power improvement.

Keywords: internal combustion engine / microbial contamination / fuel

* Correos electrónicos: darioeder@gmail.com, rcoquisc@gmail.com 


\section{CONTEXTO}

El petróleo crudo es una sustancia biodegradable que contiene una gran variedad de hidrocarburos, tales como alifáticos lineales, ramificados, cíclicos, aromáticos y compuestos heterocíclicos (Hidayat y Tachibana, 2012). El objetivo principal de extracción de petróleo es refinar el crudo y convertirlo en combustibles comerciales. Estos combustibles se utilizan en todo el mundo para la alimentación de vehículos ligeros y pesados, maquinaria pesada de servicio, grupos electrógenos, entre otros, y hacen que la industria de la refinación sea una de las más importantes en el mundo. (Gaylarde, Bento, Kelley, 1999) (Yemashova et. al., 2007).

En la industria del combustible, el mayor problema es la contaminación microbiológica de los productos almacenados, el cual puede conducir a la pérdida de la calidad, la formación de barro y el deterioro de las tuberías, tanques de almacenamiento y equipos que utilicen combustibles fósiles (Gaylarde et al., 1999; Yemashova et. al, 2007).

Los microorganismos llegan a los combustibles desde el suelo, el aire, el agua contaminada o de los tubos de transporte. Una vez allí, el agua es el requisito más importante para el crecimiento de microbios, un compuesto encontrado fácilmente en los combustibles debido a múltiples razones (ASTM, 2004a).

Aunque los informes sobre el crecimiento microbiano en este tipo de hidrocarburos han aumentado, en la actualidad no existen normas para regular la calidad microbiológica de los combustibles gastados y almacenados (Gaylarde et al., 1999). Este es el sitio principal para el crecimiento de microbios. Adicionalmente, la interface agua/combustible es el lugar donde la mayor actividad microbiana y la biodegradación de combustible se desarrolla (ASTM, 2004A).

Por otra parte, también la microflora puede producir un efecto negativo en un combustible mediante los procesos de degradación, situación que podría ser motivo de gran preocupación en el caso del kerosene (combustible de aviación), cuyo deterioro, especialmente por los hongos, ha sido referido como la principal causa de colisiones aeronáuticas (Yang Chen, Cantado, Lin, 1992) (Ferrari, Neirotti, Albornoz, 1998). Los estudios relacionados con la biodegradación de los productos derivados del petróleo concluyen que más del 80 \% están dedicados a las bacterias. Sin embargo, esta capacidad ha sido descrita en los mohos y levaduras, pero con una menor frecuencia (Atlas, 1981; Cerniglia, Cuervo, 1981; Sutherland, 2004 y Neilson, Allard, 2008). 
Debido a la falta de información sobre la contaminación microbiana en combustibles almacenados, no es posible determinar si estos niveles de degradación microbiológica tienen influencia sobre los parámetros de calidad del combustible o si se logran mantener estas propiedades dentro de los valores permisivos. Más aun, como consecuencia de la contaminación microbiana del combustible, las explosiones que ocurren en los motores a combustión interna tienden a ser incompletas, es decir, no llegan a quemar toda la energía del combustible fósil, generando subproductos tóxicos como monóxido de carbono (CO), hidrocarburos sin combustionar (HC) o humo (C).

Además, estas bacterias son bombeadas junto con el combustible hacia el motor, lo cual obstruye el filtro e inyectores de combustible, reduce su tiempo de vida y genera condiciones de operación del motor poco propicias para un eficiente funcionamiento, además de generar la necesidad del cambio prematuro de inyectores o filtros.

\section{OBJETIVOS E HIPÓTESIS ASOCIADAS AL SUSTENTO TÉCNICO}

Las hipótesis del presente trabajo son:

- Se puede detener y remediar la contaminación bacteriana en combustibles fósiles mediante la aplicación de un sistema de catalizadores EcoEvol.

- Los combustibles fósiles sometidos al tratamiento de remediación o refinación catalítica por medio del sistema de catalizadores EcoEvol mejoran la performance de motores a combustión interna.

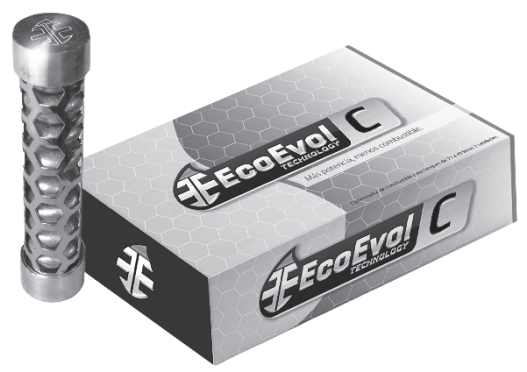

Figura 1. Catalizador EcoEvol C Elaboración propia 


\section{MARCO TEÓRICO/ESTADO DEL ARTE}

La presencia de bacterias en el combustible es una de las principales causas de averías del motor. Las bacterias y los hongos forman partículas insolubles que pueden obstruir los filtros del combustible y distintos componentes del sistema de inyección. También pueden corroer las superficies metálicas, incluyendo tanques de almacenamiento y bombas, debido a que forman ácidos orgánicos que contribuyen a exacerbar la inestabilidad de este compuesto.

Por otra parte, la reducción de la cantidad de azufre en el combustible hace que este sea vulnerable al crecimiento microbiano. Además de eliminar el oxígeno y el nitrógeno, el proceso para la eliminación de azufre de combustible requiere la introducción de agua. Cuando el combustible se contamina, el agua en el combustible diésel se convierte en un caldo de cultivo para las bacterias y los hongos (Hill y Hill, 1993).

El requisito más importante para el crecimiento microbiano en los combustibles es el agua, la que casi siempre está presente, por las siguientes razones:

1) La humedad ambiental puede condensarse en las paredes del tanque y mezclarse con el combustible.

2) La humedad en el aire puede entrar a través de las tapas de los tanques flotantes $u$ otros respiraderos.

3) El mal diseño de los tanques no drena el agua de manera eficiente.

4) Se puede añadir agua como lastre (en barcos) o para purgar el sistema de suministro.

Además, el oxígeno está normalmente presente en cantidades suficientes en los tanques de combustibles destilados, y se repone continuamente cuando se rellenan. Sin embargo, aunque el combustible se convierte en anaeróbico, no está protegido contra el ataque microbiano, ya que los organismos facultativos, tales como Hormoconisresinae, y otros anaerobios continúan prosperando. El factor limitante para el crecimiento es, probablemente, la disponibilidad de minerales, en particular de fósforo, que está generalmente presente a $<1$ ppm en el combustible. El nitrógeno y el hierro también pueden ser importantes nutrientes limitantes (Rajasekar, Maruthmuthu, Palaniswamy y Rajendram, 2007).

Muchos estudios de laboratorio han demostrado que los hongos crecen mucho más fácilmente en un sistema de combustible que contiene 
solución de sales minerales como fase acuosa que con agua, o incluso el agua de drenaje del tanque. Sin embargo, además de los minerales que entran en el agua y otros contaminantes aéreos, muchos de los aditivos que ahora se utilizan en la industria de los combustibles contienen estos elementos minerales vitales para la evolución microbiana (Rajasekar et al., 2007).

Los microorganismos pueden entrar en el combustible desde el suelo, a través de diferentes medios como el aire, agua de lavado contaminada, tuberías contaminadas o de biopelículas presentes en las paredes del tanque que no han sido correctamente limpiadas. No todos los organismos son capaces de metabolizar hidrocarburos: algunos sobreviven simplemente por catabolismo, además de los hidrocarburos. Los organismos pueden obtener los nutrientes de los aditivos de combustible, de la suciedad que entra en el sistema o desde el crecimiento de organismos que colonizan primarios. Las cadenas de hidrocarburos utilizados más fácilmente son hidrocarburos de cadenas del tiempo C10-C18 (Rodríguez, Rodríguez, Blanco, Cordero, Segura, 2010).

Existen tecnologías que buscan solucionar el problema de las bacterias en el combustible, como es el caso de los filtros. Estos suelen ser membranas con pequeños poros por los cuales se fuerza a pasar el combustible aplicando presión, de tal manera que las impurezas se queden atrapadas en la membrana. Pero esta tecnología tiene deficiencias como generar presión transmembrana significativa, lo que vuelve ineficiente el sistema de bombeo e inyección de combustible y lleva a que se necesite mayor trabajo de la bomba producto de la saturación de la membrana de impurezas. Por otra parte, en algunas situaciones, el tamaño de los poros puede ser más grande que las bacterias. Por ello, algunas bacterias logran atravesar el filtro y llegar a los inyectores, generando la formación de gomas en los mismos, obstruyendo sus orificios y propiciando una ineficiente inyección del combustible.

Para impedir la formación de bacterias y eliminar su presencia en combustibles fósiles se han diseñado aditivos (actualmente existen distintas marcas comerciales en el mercado). Pero estos aditivos no dan un tratamiento permanente al combustible, tan solo tratan un volumen específico de combustible, que debe ser repuesto cada vez que se consuma, y su composición desestabiliza la mezcla del combustible, por lo que se pierde cetanaje u octanaje, lo que compromete negativamente la calidad de la combustión. Esto se traduce en pérdida de potencia y aumento del consumo de combustible. 


\section{METODOLOGÍA UTILIZADA PARA VALIDAR LA TECNOLOGÍA}

Para validar el efecto bactericida del catalizador EcoEvol sobre el combustible y su efecto en la mejora de la performance en motores de combustión interna, se realizaron las pruebas de cuantificación de absorbancia mediante espectrofometría UV-VIS en muestras de gasolina y diésel, medición de índice de cetanos y ensayos de motor en un banco de pruebas de laboratorio.

\section{- Pruebas de espectrofotometría}

Se almacenó una muestra de gasolina de 90 octanos por siete meses en un recipiente oscuro con una pequeña abertura para el ingreso del aire. Transcurrido este plazo, se observó la aparición de partículas sólidas en el fondo del recipiente, lo que evidencia la aparición de bacterias. Luego se tomaron $700 \mathrm{ml}$ de combustible contaminado para someterlo a un sistema de recirculación continua, en el cual se encontraron contenidos los catalizadores EcoEvol C. Antes de que empiece la recirculación, se tomó una muestra. Luego, se inició el proceso y se analizaron muestras cada día por un lapso de cuatro días; estas muestras se toman en un ambiente oscuro, ya que la gasolina de 90 octanos tiene componentes sensibles a la luz que pueden alterar los resultados.

De la misma manera, se almacenó combustible DB5 (diésel) de color verde transparente por siete meses en un recipiente oscuro con una pequeña abertura para el ingreso del aire. Se observó la aparición de partículas sólidas en el fondo del recipiente, el cual tomó un color verde oscuro, lo que evidencia la aparición de bacterias. Luego, se tomaron $700 \mathrm{ml}$ de combustible contaminado para someterlo a un sistema de recirculación continua, en el que se encontraron contenidos los catalizadores EcoEvol C. Antes de que empiece la recirculación, se analizó una muestra. Después, se dejó recircular el combustible y se analizó una muestra cada día por un lapso de seis días. Asimismo, se tomó una fotografía del combustible antes de tomar cada muestra, para evidenciar el cambio de las propiedades del mismo.

Todas las muestras se analizaron mediante el método de espectroscopia UV-VIS, que consiste en someter una muestra de un líquido a un rayo de luz de cierta longitud de onda $(\mathrm{nm})$, con el objetivo de cuantificar la cantidad de luz que es absorbida por los compuestos disueltos en el medio líquido. La cantidad de luz absorbida es conocida 
como absorbancia, la que tiene una correlación directa con la concentración de los compuestos presentes.

Cada muestra fue sometida a un barrido espectrofotométrico que abarcó una luz con longitud de onda desde $800 \mathrm{~nm}$ hasta $387 \mathrm{~nm}$, para cuantificar las concentraciones de contaminantes totales presentes en la gasolina de 90 octanos y diésel fresco. Para ello, se realizó un barrido espectrofotométrico en las mismas longitudes de onda. De esta manera se conoce la concentración inicial de una gasolina comercial. Así, para determinar la concentración de contaminantes que aparecieron a partir del proceso de deterioro del combustible (aquel que tomó siete meses), se restan los resultados del barrido espectrofotométrico de la gasolina y diésel fresco a los valores de cada muestra de la gasolina y diésel deteriorado y tratado. De esta manera, se obtuvo la señal de las bacterias formadas durante el proceso de degradación bacteriana del combustible y cómo estas bacterias desaparecen por el efecto del catalizador.

\section{- Pruebas con el motor en el banco de pruebas}

Para el análisis y contraste de la operación de un motor de combustión interna con combustible sin tratar y tratado, se utilizó un motor Ford ZSG414 (cuatro cilindros en línea, 1600cc) acoplado a un banco de pruebas Gunt Hamburg Serie CT400 para controlar el paquete de sensores que miden las variables potencia $(\mathrm{kW})$, torque $(\mathrm{nm})$, consumo horario $(\mathrm{kg} / \mathrm{h})$ y consumo específico $(\mathrm{g} / \mathrm{kW})$

Además, se utilizó un analizador de gases de marca Saxon y modelo Infralit CL para cuantificar las variables: lambda $(\lambda), \mathrm{CO}$ (\%vol), $\mathrm{CO}_{2}$ (\%vol) y $\mathrm{HC}(\mathrm{ppm})$.

Se tomaron mediciones de los parámetros antes indicados, considerando los siguientes regímenes de velocidad del motor a:

- Ralentí (800 rpm) (sin activar freno electromagnético)

- 1500 rpm (freno electromagnético activado a $50 \%$ )

- $2000 \mathrm{rpm}$ (freno electromagnético activado a 50 \%)

- $2350 \mathrm{rpm}$ (freno electromagnético activado a $50 \%$ )

- $2500 \mathrm{rpm}$ (freno electromagnético activado a 50 \%)

El motor fue arrancado y acelerado levemente hasta alcanzar la temperatura estándar de operación (de aproximadamente $90^{\circ} \mathrm{C}$ ). Una vez alcanzada la temperatura deseada, se realizaron las mediciones en ralentí. Luego, se procedió a acelerar el motor y activar el 
freno electromagnético al $50 \%$ de su capacidad, para generar condiciones de carga elevada. Las mediciones fueron realizadas para las condiciones anteriormente descritas. Finalmente, se procedió a desacelerar el motor, desactivar el freno electromagnético y apagar el motor. Se instaló el catalizador de combustible EcoEvol C en el tanque de combustible. Se esperó 45 minutos a que el combustible reaccione y se encendió el motor, haciéndolo funcionar en ralentí para que retome la temperatura indicada para su funcionamiento. Una vez alcanzada la temperatura deseada, se repitieron las mediciones para las condiciones anteriormente descritas.

\section{ANÁLISIS DE LA EFECTIVIDAD O DE LOS RESULTADOS DE LA EVALUACIÓN DE LA TECNOLOGÍA}

\section{- Resultado de pruebas de espectrometría}

Se realizaron las pruebas espectrofotométricas por cada día que se tomó las muestras de gasolina de 90 octanos, como se ve en la figura 2.

En la figura 2 se observa un pico de absorción a $424 \mathrm{~nm}$, el cual indica la presencia de bacterias. La gasolina de 90 octanos presentaba un color rojizo transparente antes de la contaminación, y después de la contaminación presenta un color rojo oscuro turbio, no transparente, con partículas sólidas en el fondo. Se observa que la gasolina contaminada presenta un cambio de color al ser sometida al proceso de descontaminación mediante el uso de los catalizadores EcoEvol C, el cual se verifica en la disminución de absorbancia a $424 \mathrm{~nm}$.

En la tabla 1 se presenta la caída de absorbancia, que al segundo día ya empieza a aclararse. La disminución de absorbancia es de $62 \%$, lo cual indica que hay una disminución aproximada del $62 \%$ de partículas de origen bacteriano. Esta disminución sigue al cuarto día, en el que llega al 26,3 \%, y se obtiene una disminución de partículas de origen bacteriano, debido al tratamiento del catalizador EcoEvol C. 


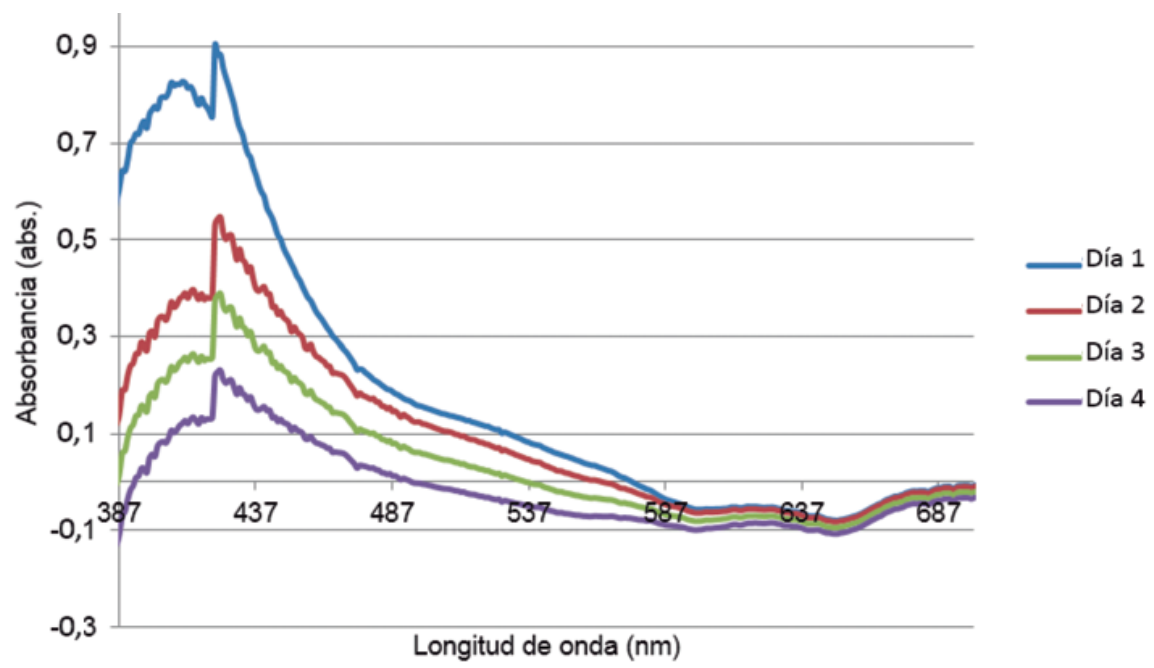

Figura 2. Espectrofotometría uv-vis de muestras de combustibles de 90 octanos contaminado tratados con el catalizador EcoEvolC Elaboración propia

Tabla 1

Resultados del análisis por espectroscopia UV-VIS de la gasolina de 90 octanos

\begin{tabular}{ccccc}
\hline Muestra & $\begin{array}{c}\text { Tiempo } \\
\text { (día) }\end{array}$ & $\begin{array}{c}\text { Longitud } \\
\text { de onda }\end{array}$ & $\begin{array}{c}\text { Absorbancia } \\
\text { (abs.) }\end{array}$ & $\begin{array}{c}\text { Disminución de } \\
\text { absorbancia (\%) }\end{array}$ \\
\hline 1 & 1 & 424 & 0,883 & 100,0 \\
2 & 2 & 424 & 0,547 & 62,0 \\
3 & 3 & 424 & 0,388 & 44,0 \\
4 & 4 & 424 & 0,231 & 26,3 \\
\hline
\end{tabular}

Elaboración propia

Se realizaron las pruebas espectrofotométricas por cada día que se tomó las muestras para la muestra de gasolina de DB5 (figura 3).

En la figura 3 se observa un pico de absorción a $383 \mathrm{~nm}$, el cual indica la presencia de bacterias. El combustible DB5 antes de la contaminación presentaba un color verde transparente, y después de la contaminación presenta un verde oscuro turbio, no transparente, con partículas sólidas en el fondo. El combustible contaminado muestra un cambio de color al ser sometido al proceso de descontaminación utilizando los catalizadores EcoEvol C, el cual se verifica en la disminución de absorbancia a $383 \mathrm{~nm}$. En la tabla 2 se presenta la caída 
de absorbancia, que al segundo día ya empieza a aclararse, con una disminución de absorbancia de 78,6 \%, lo que indica que hay una disminución aproximada del 78,6 \% de partículas de origen bacteriano. Esta disminución continúa hasta el sexto día de tratamiento, en el que llega al 12,4\%, y obtiene una disminución de partículas de origen bacteriano al utilizar el catalizador EcoEvol C. Estos resultados se observan en las figuras 3 y 4 .

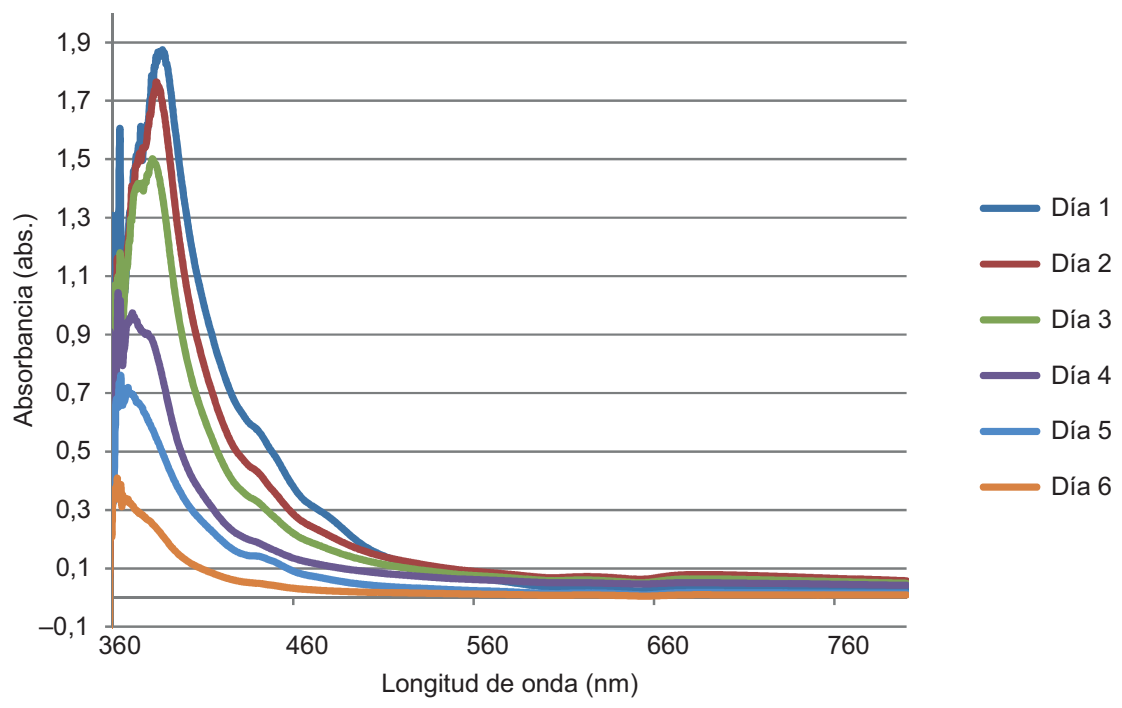

Figura 3. Espectrofotometría uv-vis de muestras de combustibles DB5 contaminado tratados con el catalizador EcoEvolC Elaboración propia

Tabla 2

Resultados del análisis por espectroscopia UV-VIS del combustible DB5

\begin{tabular}{ccccc}
\hline Muestra & $\begin{array}{c}\text { Tiempo } \\
\text { (día) }\end{array}$ & $\begin{array}{c}\text { Longitud } \\
\text { de onda }\end{array}$ & $\begin{array}{c}\text { Absorbancia } \\
\text { (abs.) }\end{array}$ & $\begin{array}{c}\text { Disminución } \\
\text { de absorbancia (\%) }\end{array}$ \\
\hline 1 & 1 & 383 & 1,867 & 100,0 \\
2 & 2 & 383 & 1,729 & 92,6 \\
3 & 3 & 383 & 1,460 & 78,2 \\
4 & 4 & 383 & 0,817 & 43,8 \\
5 & 5 & 383 & 0,533 & 28,5 \\
6 & 6 & 383 & 0,232 & 12,4 \\
\hline
\end{tabular}

Elaboración propia 


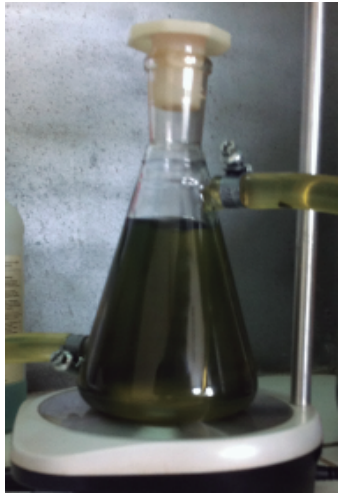

(a)

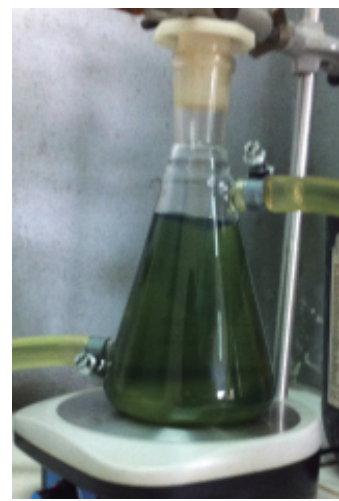

(b)

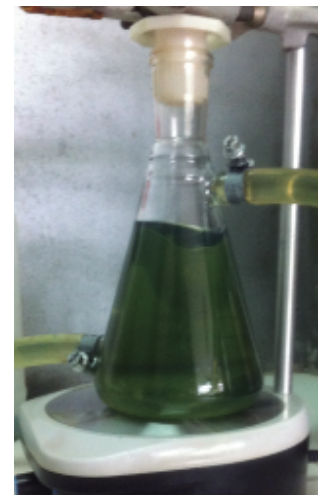

(c)

Figura 4. Proceso de eliminación de las bacterias presentes en el combustible DB5 usando el catalizador EcoEvol C; a) día 1, b) día 2 y c) día 3

Elaboración propia

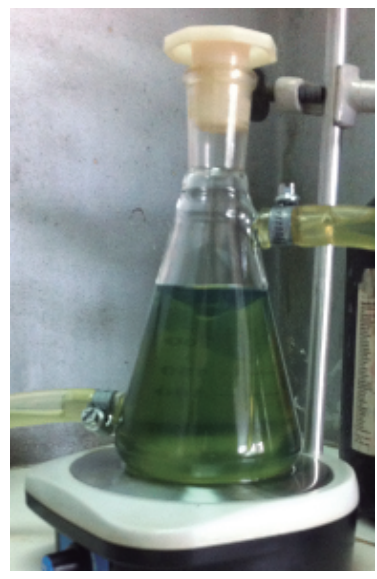

(d)

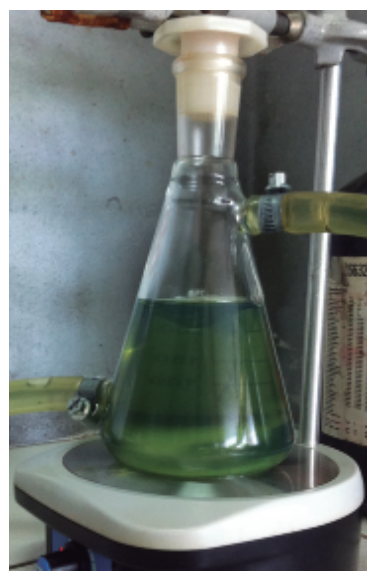

(e)

Figura 5. Proceso de eliminación de las bacterias presentes en el combustible DB5 usando el catalizador EcoEvol C; día 5, y día 6

Elaboración propia

- Resultado de las pruebas del motor en el banco de pruebas de laboratorio

En la tabla 3 se muestran los resultados de las mediciones realizadas en el motor de pruebas (Temperatura ambiental: $20^{\circ} \mathrm{C} / \mathrm{Humedad}$ relativa $90 \%$ ). 


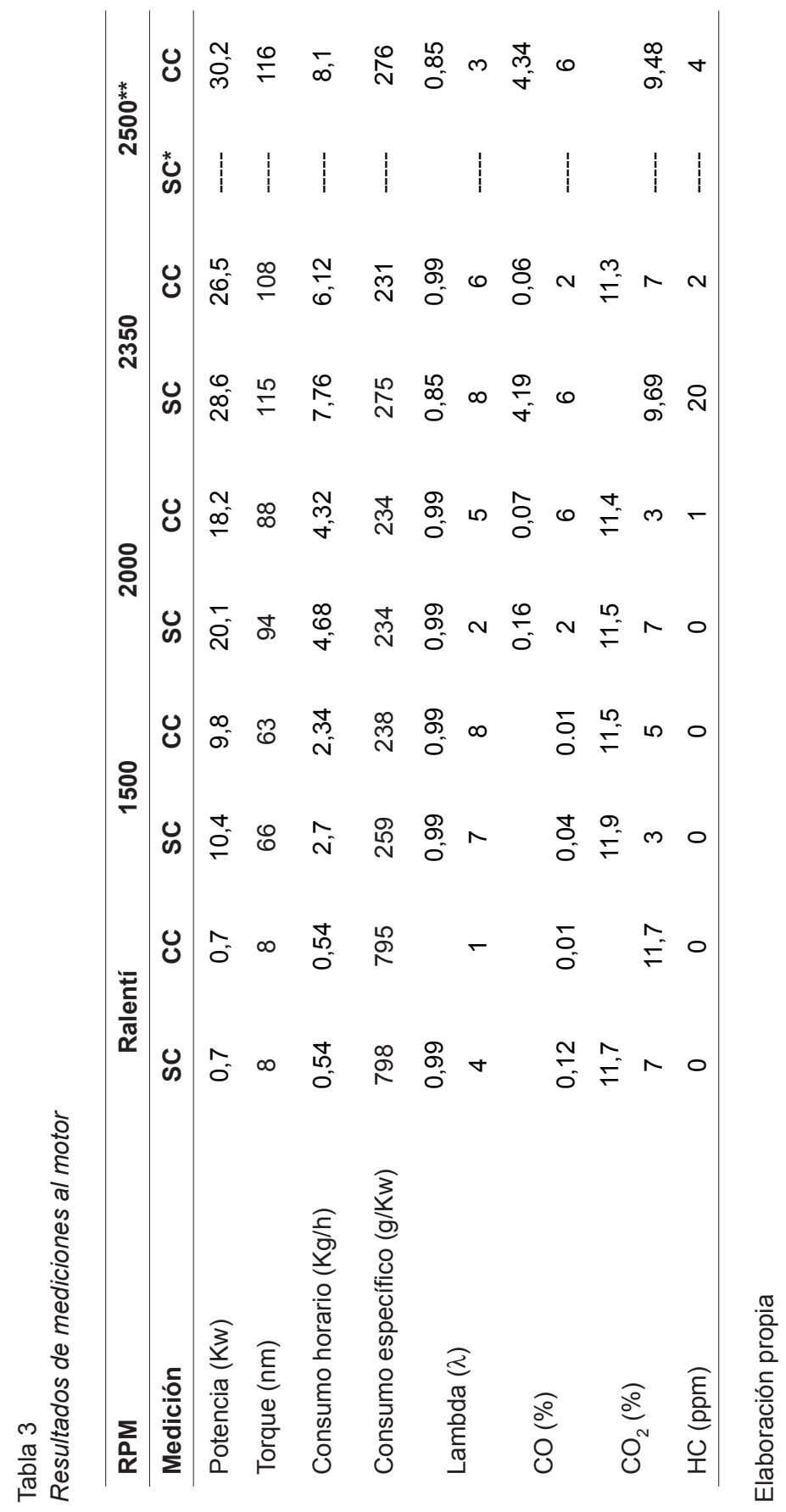




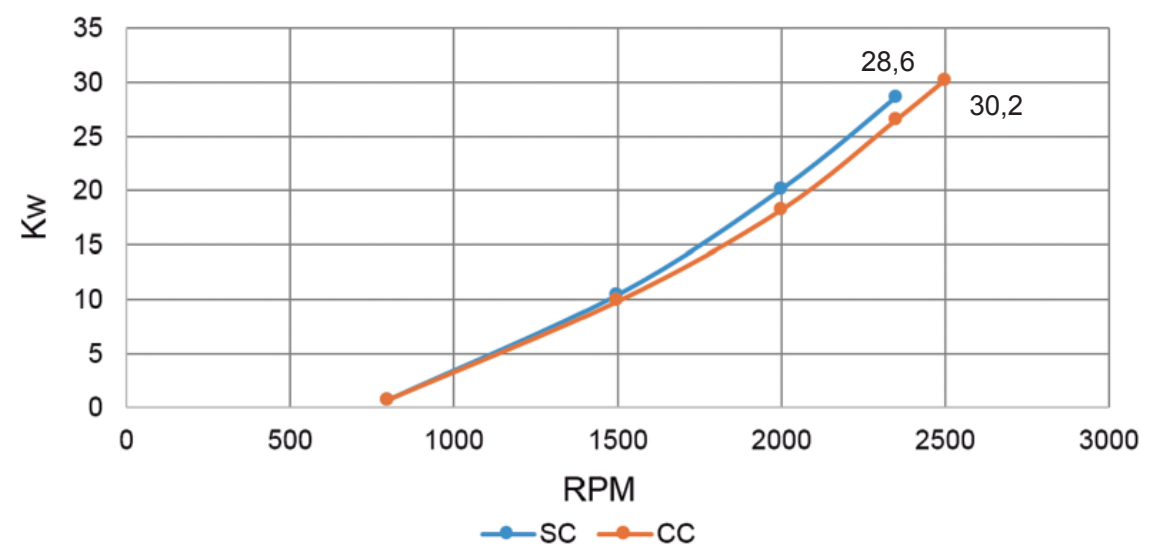

Figura 6. Potencia en régimen de velocidad Elaboración propia

Se puede apreciar que la potencia máxima alcanzada con el catalizador es 5,2\%, superior a la potencia estándar del motor. También se observa que la potencia desarrollada con el catalizador en distintos regímenes de rpm aplicando la misma fuerza de frenado del banco de pruebas fue menor. Esto significa que la eficiencia mecánica del motor aumentó y que ahora requiere menor potencia para vencer una misma fuerza.

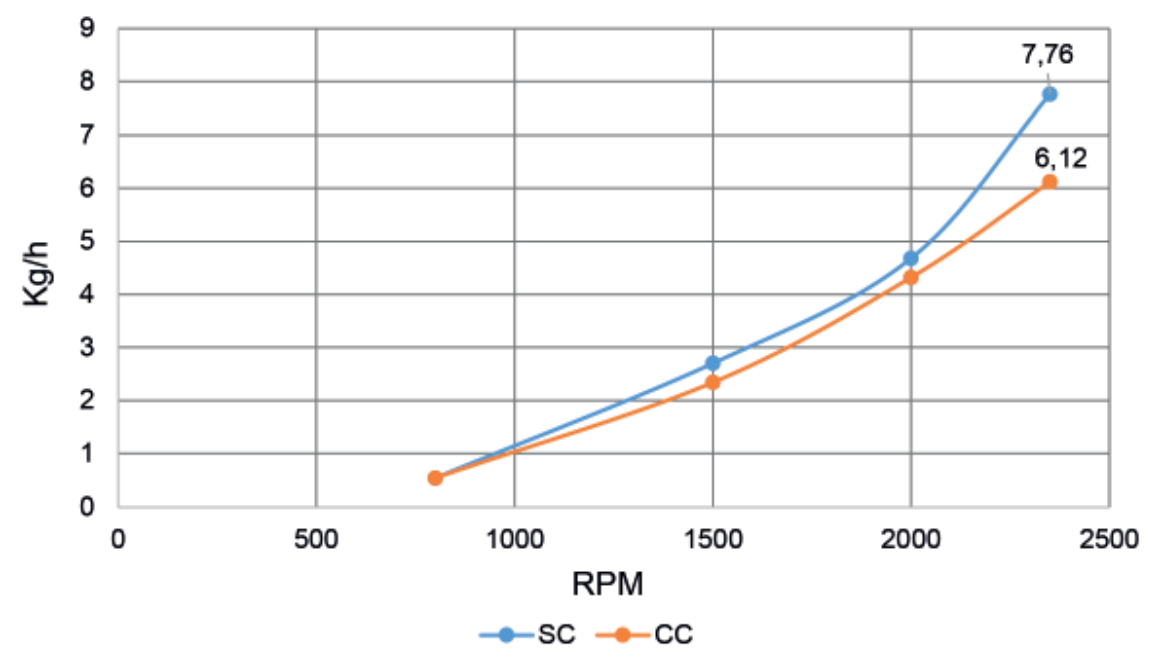

Figura 7. Consumo horario en régimen de velocidad Elaboración propia 
El consumo de combustible se redujo en todos los regímenes de rpm, y la reducción más significativa fue en el régimen máximo de exigencia del motor, en el que se obtuvo una reducción de $26,7 \%$.

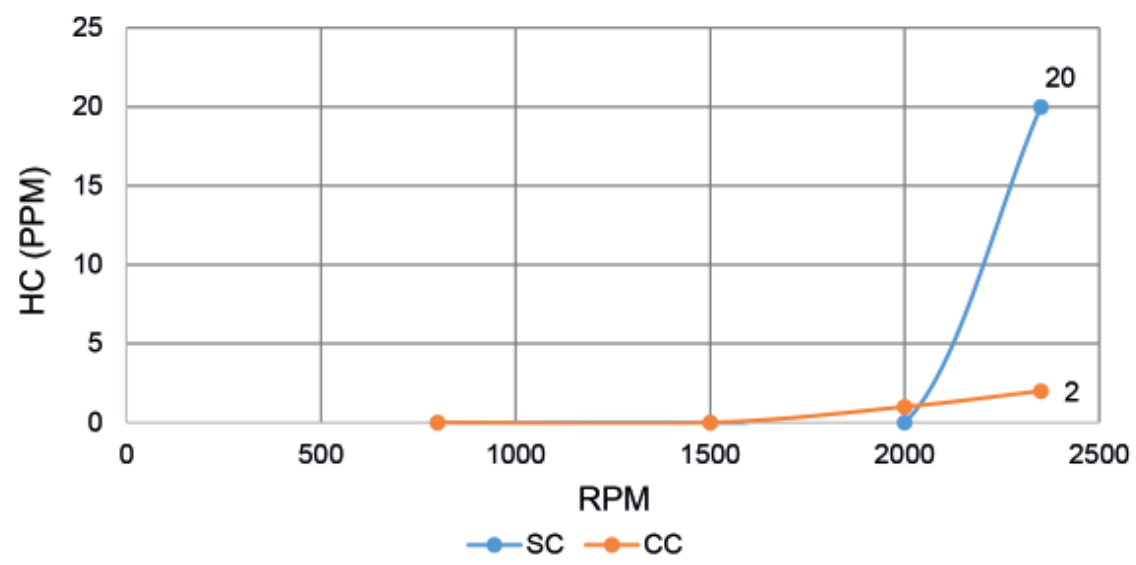

Figura 8. Emisiones de hidrocarburos en régimen de velocidad Elaboración propia

Las emisiones de hidrocarburos se redujeron en todos los regímenes de rpm, y la reducción más significativa fue en el régimen máximo de exigencia del motor, en el que se obtuvo una reducción de $90 \%$.

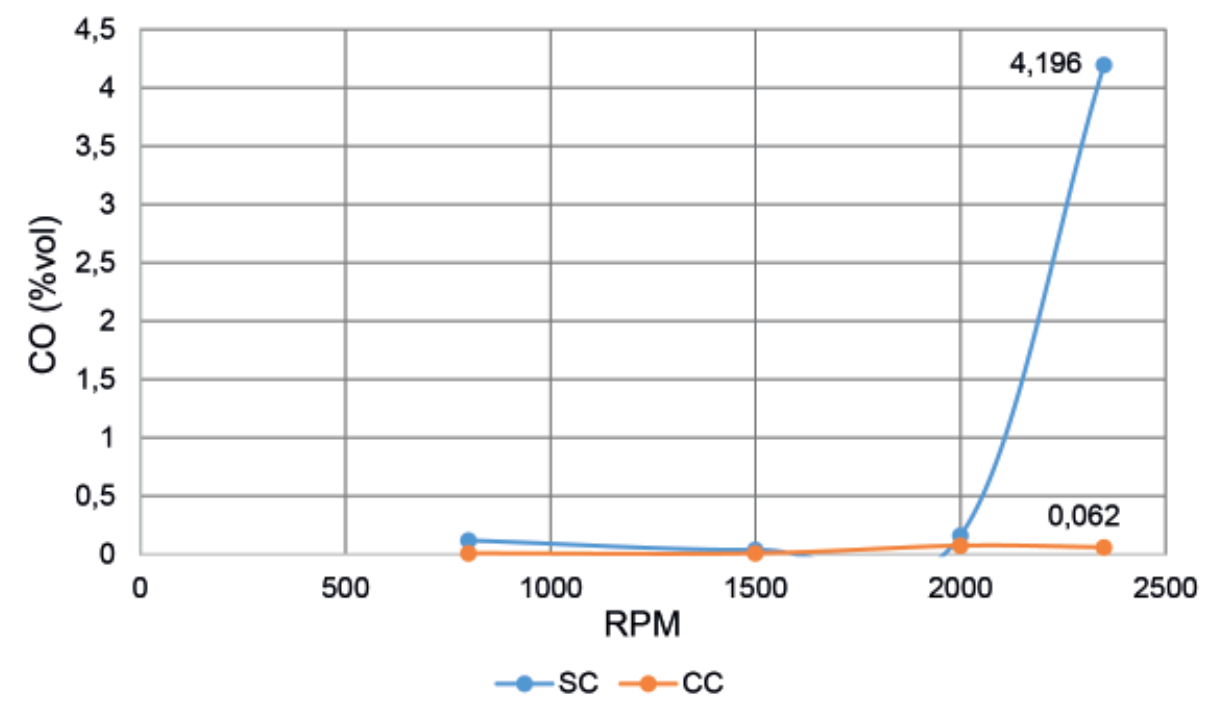

Figura 9. Emisiones de monóxido de carbono en régimen de velocidad Elaboración propia 
Como se ve, las emisiones de hidrocarburos se redujeron en todos los regímenes de rpm, y la más significativa se presentó en el régimen máximo de exigencia del motor, en el que se obtuvo una reducción de 98,5 \%. Además, utilizando el catalizador, el régimen máximo de rpm alcanzado por el motor fue $2500 \mathrm{rpm}$, mientras que sin el catalizador el motor alcanzó $2350 \mathrm{rpm}$. Asimismo, la señal lambda presentó mayor estabilidad y cercanía al valor 1 cuando el catalizador estuvo instalado en el motor.

\section{APLICACIONES REALIZADAS Y OPORTUNIDADES DE APLICACIÓN}

Además de los ensayos en laboratorio, se realizaron pruebas de campo con vehículos de tres tipos: ligeros cero kilómetros, maquinaria minera y camiones de carga, con el objetivo de cuantificar el ahorro de combustible y la posibilidad de usar gasolina de menor octanaje, cuantificar la reducción de emisiones de monóxido de carbono y medir la reducción de la opacidad, respectivamente.

En el caso de las pruebas con vehículos cero kilómetros, se instaló una cantidad suficiente de catalizadores EcoEvol C, vehículos de modelo Mazda CX-9, Suzuki Kizashi y Suzuki Nomade, y se obtuvo una reducción promedio de $12 \%$ del consumo de combustible en promedio y se logró utilizar combustible de 90 octanos en todos los casos, a pesar de que lo motores de dichos vehículos han sido diseñados para usar gasolina de 95 o 97 octanos. Las pruebas fueron realizadas en un recorrido urbano de 6000 kilómetros.

En las pruebas realizadas en maquinaria minera, se instaló una cantidad suficiente de catalizadores EcoEvol C en un camión de marca Mitsubishi Fuso de ocho meses de uso en las operaciones de un campamento minero. Este camión presentaba emisiones de monóxido de carbono con un promedio de 750 ppm. Después de cinco días de instalar el catalizador, las emisiones de monóxido se redujeron hasta alcanzar un promedio de $460 \mathrm{ppm}$. Esto tiene un valor significativo, dado que con esta tecnología se pudo alcanzar los requerimientos mínimos solicitados por el marco legal que regula las operaciones de minería subterránea (DS - N. . 055-2010-EM). Las mediciones de la concentración de monóxido fueron realizadas con un equipo Drager EM200-E. 


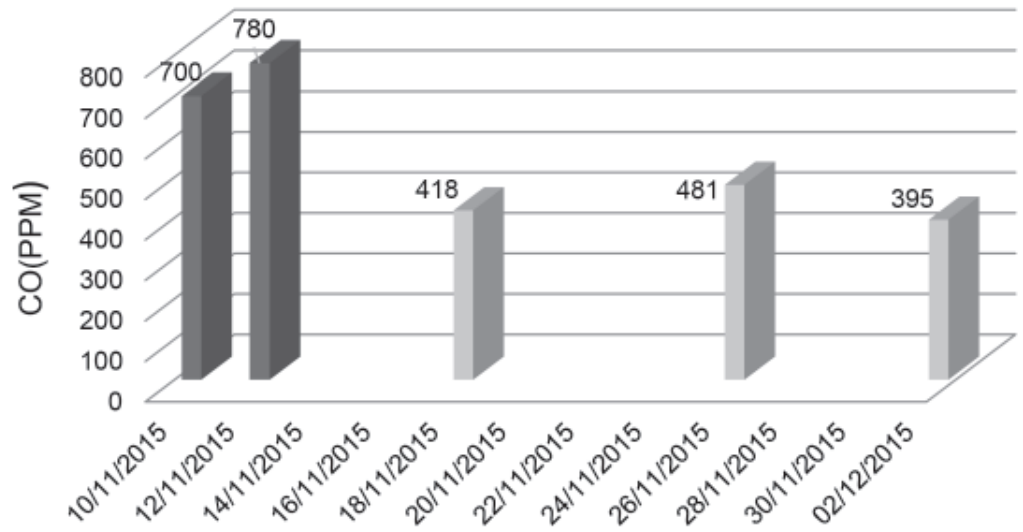

Figura 10. Emisiones de monóxido de carbono en camión minero con respecto al tiempo Elaboración propia

Finalmente, las pruebas realizadas con camiones de carga diésel tuvieron el objetivo de cuantificar la reducción de opacidad a la hora de instalar el catalizador EcoEvol C en una de sus unidades. Se realizaron medidas de opacidad antes y después de haber instalado los catalizadores, y se obtuvieron los siguientes resultados:

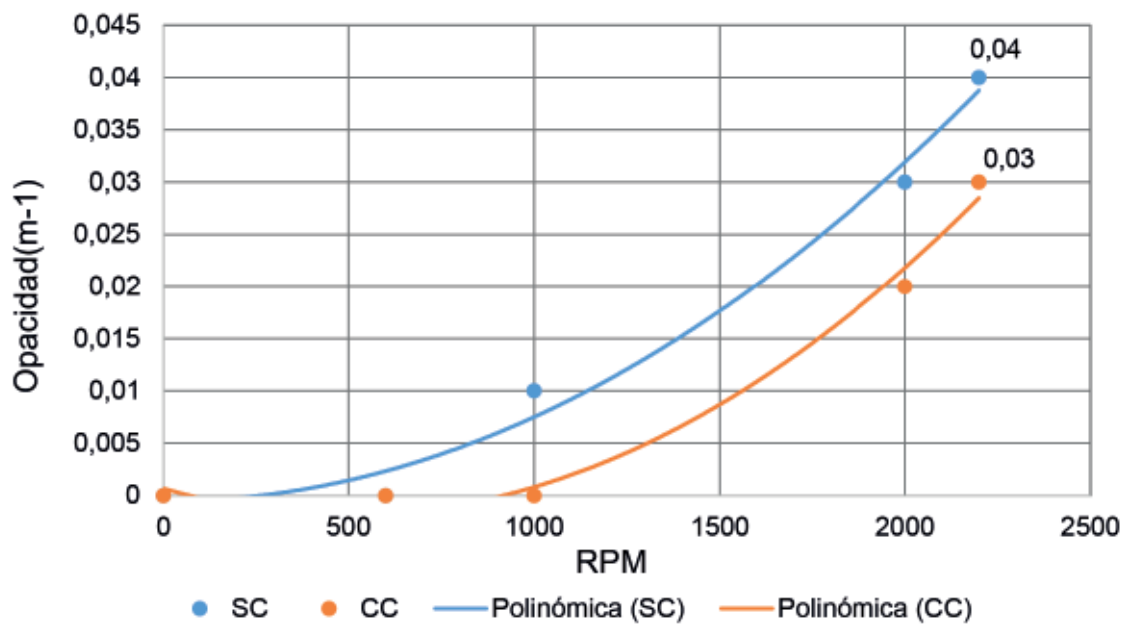

Figura 11. Opacidad en régimen de velocidad Elaboración propia 
Las emisiones de humo u opacidad se redujeron en todos los regímenes de rpm, y la reducción más significativa se registró en el régimen máximo de exigencia del motor, en el que se obtuvo una reducción de $33 \%$.

\section{CONCLUSIONES}

- Mediante los resultados de la prueba obtenida por espectrofotometría UV-VIS, se logró validar la reducción de contaminantes en la gasolina de 90 octanos, de la misma manera que en el combustible DB5, y se logró restaurarlo a su estado inicial mediante el uso del catalizador EcoEvol C.

- A partir de las experiencias realizadas con motores de laboratorio y pruebas de campo, se demostró que la aplicación del catalizador EcoEvol $\mathrm{C}$ reduce la emisión de gases tóxicos de escape, reduce el consumo de combustible y aumenta la potencia del motor.

- La aplicación de los catalizadores EcoEvol C en sistemas de almacenamiento e inyección de combustible de maquinaria ligera y liviana favorecerá el funcionamiento del motor y preservará la vida útil y correcto funcionamiento de piezas como la bomba de combustible, los inyectores y los filtros de combustible.

- La aplicación de catalizadores EcoEvol no se limita a la aplicación en vehículos motorizados, ya que puede ser instalado en tanques o silos de combustible para preservar y mejorar su calidad durante el almacenamiento o transporte del mismo.

- La aplicación de catalizadores EcoEvol C ayuda a que la maquinaria de aplicación de minería subterránea cumpla con los lineamientos del DS N. ${ }^{\circ} 055$-2010-EM.

\section{REFERENCIAS}

ASTM. (2004). La norma ASTM D 6469: Guía para contamination microbiana en combustibles y sistemas de combustible. La Sociedad Americana para Pruebas y Materiales Internacionales, West Conshohocken, PA.

Atlas, R. M. (1981). La degradación microbiana del petróleo hydrocarbonos: una perspectiva ambiental. Exámenes Microbiológicos, 45, 180-209. 
Cerniglia, C. E. S. y UN Cuervo, (1981). Metabolismo del aromático hidrocarbonos por levaduras. Archivos de Microbiología, 129, 9-13.

Ferrari, M. D., Neirotti, E., y Albornoz, C. (1998). La aparición de bacterias heterótrofas y hongos en un sistema de manejo de combustible de aviación y su relación con el combustible está sucio. Revista Argentina de Microbiología, 30, 105-114.

Gaylarde, C. C., Bento, F. M., y Kelley, J. (1999). Microbial Contamination of Stored Hydrocarbon Fuels and its Control. Revista de Microbiologia, 30(1), 1-10.

Hidayat, A y Tachibana, S. (2012). Bioremediation of Aliphatic Hydrocarbon in Three Types of Crude Oil by Fusarium sp. F092 under Stress with Artificial Sea Water. Journal of Environmental Science and Technology, 5(1), 64-73.

Hill, C. E, y Hill, G. C. (1993) .Microbiological problems in stilled fuels. Trans. Inst. Marina Eng., 104, 119-130

Neilson, B; y Allard, A. S. (2008). La degradación ambiental y la transformación de los productos químicos orgánicos. Florida: CRC Press, Taylor \& Francis Group.

Rajasekar, A., Maruthmuthu, S., Palaniswamy, N., y Rajendram, A. (2007). Biodegradación de los inhibidores de la corrosión y su influencia en la cartera de productos de petróleo. Investigación Microbiológica, 162, 355-368.

Rodríguez, R. C. E; Rodríguez, E., Blanco, R., Cordero, I., y Segura, D. (2010). Fungal la contaminación de automóviles-combustibles almacenados en un ambiente tropical. Journal of Environmental Sciences, 22, 1595-1601.

Ruma Ghosh. (s. f.). Estudio del efecto de Fitch catalizador de combustible microbiana de combustible diésel contaminado. Boletín Técnico de la Universidad de Connecticut, 4.

Sutherland, J. B. (2004). La degradación de los hidrocarburos por levaduras y hongos filamentosos. En: Hongos en la biotecnología agrícola, alimentaria y aplicaciones ambientales. (Arora, D. K., Puente, P. D., Bhatnagar, D., eds.). 417-429. New York: Marcel Dekker. 
Yang Chen, S. S. C., Cantado, Y., y Lin, Y. T. (1992). Ect E ff de humedad Contenido de la actividad microbiana en aceite combustible JP-5. La Revista China de Microbiología e Inmunología, 25, 223-231.

Yemashova, N. A., Murygina, V. P., Zhukov, D. V., Zakharyantz, A. A., Gladchenko, M. A., Appanna, V., y Kalyuzhnyi, S. V. (2007). Biodeterioration of Crude Oil and Oil Derived Products: a Review. Reviews in Environmental Science and Biotechnology, 6(4), 315-337. 
